\title{
Outcome and quality of life after aorto-bifemoral bypass surgery
}

Fernando J Abelha ${ }^{1 *}$, Miguela Botelho ${ }^{1}$, Vera Fernandes ${ }^{1}$, Henrique Barros ${ }^{2}$

\begin{abstract}
Background: Aorto-bifemoral bypass (AFB) is commonly performed to treat aorto-iliac disease and a durable longterm outcome is achieved. Most studies documenting beneficial outcomes after AFB have been limited to mortality and morbidity rates, costs and length of hospital stay (LOS). Few studies have examined the dependency of patients and how their perception of their own health changes after surgery. The aim of the present study was to evaluate outcome after AFB and to study its determinants.
\end{abstract}

Methods: This retrospective study was carried out in the multidisciplinary Post-Anaesthesia Care Unit (PACU) with five intensive care beds. Out of 1597 intensive care patients admitted to the PACU, 75 were submitted to infrarenal AFB and admitted to these intensive care unit (ICU) beds over 2 years. Preoperative characteristics and outcome were evaluated by comparing occlusive disease with aneurysmatic disease patients. Six months after discharge, the patients were contacted to complete a Short Form-36 questionnaire (SF-36) and to have their dependency in Activities of Daily Living (ADL) evaluated. Patient's characteristics and postoperative follow-up data were compared using Mann-Whitney $\mathrm{U}$ test, $\mathrm{t}$ test for independent groups, chi-square or Fisher's exact test. Patient preoperative characteristics were evaluated for associations with mortality using a multiple logistic regression analysis.

Results: The mortality rate was $12 \%$ at six months. Multivariate analysis identified congestive heart disease and APACHE II as independent determinants for mortality. Patients submitted to AFB for occlusive disease had worse SF-36 scores in role physical and general health perception. Patients submitted to AFB had worse SF-36 scores for all domains than a comparable urban population and had similar scores to other PACU patients. Sixty-six percent and $23 \%$ of patients were dependent in at least one activity in instrumental and personal ADL, respectively, but $64 \%$ reported having better general health.

Conclusion: This study shows that congestive heart disease and APACHE II were risk factors for mortality after AFB surgery. Survivors who have undergone AFB perceive an improved quality of life although they are more dependent in ADL tasks and have worse scores in almost all SF-36 than the population to which they belong.

\section{Background}

Although some studies have documented beneficial outcome after aorto-bifemoral bypass (AFB) surgery, most have been limited to mortality and morbidity rates, cost and length of hospital stay (LOS) [1,2]. Few studies have examined the dependency of these patients and how they perceive changes in their own health after this procedure, and little is known about the extent and impact of these changes on patient outcome.

In this study we review the characteristics of patients undergoing $\mathrm{AFB}$, studying outcomes up to six months

\footnotetext{
* Correspondence: abelha@mail.telepac.pt

${ }^{1}$ Department of Anesthesia, Hospital de São João, Porto, Portugal
}

after the procedure, when dependency on Activities of Daily Living (ADL) and health related quality of life were evaluated. For this study we considered patients who were submitted to scheduled or emergent surgery for either an abdominal aortic aneurysm or arterial occlusive disease.

We considered the stratification of patients according to cardiac risk factors [3] which some authors regard as predictors of mortality or LOS.

Several questionnaires have been validated for the study of Health Related Quality of Life [4-8]. Most of the measures that have been used are multi-item scales; that is, they comprise several questions or items. Some multiple-item scales provide a total score as well as 
generating subscales that provide information on particular aspects such as mobility. The Short-Form General Health Survey (SF-36) was developed during the Medical Outcomes Study (MOS) to measure general health concepts relevant across age, disease and treatment groups [9]. It is a self-completed questionnaire covering all aspects of Health Related Quality of Life (HRQOL). It is a valid instrument for measuring HRQOL. It has been used for post-discharge ICU patients and for studying groups with other diseases; it shows good reliability and validity $[9,10]$. This questionnaire was culturally adapted to Portuguese and validated in a study by Ferreira[11,12].

Low functional status puts patients at higher risk. Patients with only minor or no clinical predictors but with poor functional capacity are recommended to undergo noninvasive testing prior to this surgery. The ability to care for oneself and live independently has been considered a measure of functional outcome after hospitalization [13]. Functional status refers to the level of involvement in activities and is often used as a synonym for performance in ADL [14]. ADL appraisal scales consider functional and instrumental activities. A patient's ability to handle these activities has been assessed by generic or disease-specific measures of physical functional status. Katz's Activities of Daily Living Scale[14] and the Lawton Instrumental Activities of Daily Living [15] have been investigated in critical care survivors.

The determination of functional outcome and the identification of predictors of survival and functional recovery after AFB may be fundamental for evaluating the needs of these patients and promoting proper treatment.

The aim of the present study was to evaluate quality of life and independence in activities of daily living in patients submitted to AFB surgery.

\section{Methods}

The Institutional Review Board of the Hospital de São João approved the study protocol and written consent was obtained from the patients or members of their families.

This retrospective cohort study was carried out in the multidisciplinary Post-Anaesthesia Care Unit (PACU) at the Hospital São João, an 1124-bed community teaching hospital in Porto, Portugal, over a period of two years beginning in March 2006. Included in the PACU was a Surgical Intensive Care Unit with five beds to which critically ill surgical patients are admitted and are closely monitored and treated.

All consecutive postoperative patients admitted to the surgical ICU area of the PACU, who were submitted electively for aorto-bifemoral bypass surgery for either infrarenal abdominal aortic aneurysm or arterial occlusive disease, were enrolled. Patients who were readmitted during the study period were included only on the first admission.

Patients were excluded from the study if the procedure was performed to treat a symptomatic or ruptured abdominal aortic aneurysm or if cross-clamping above the renal arteries was required.

The following clinical variables were recorded on admission to the ICU: age, sex, body weight and height and ASA physical status. At admission, the core temperature was registered using a tympanic thermometer and a sample of blood was taken to measure troponin I. The ICU and in-hospital LOS and mortality were also recorded for all patients, and the Score of Simplified Acute Physiology Score (SAPS) II [16] and Acute Physiology \& Chronic Health Evaluation (APACHE) II [17] were calculated using standard methods.

Specifically, preadmission comorbidities, any history of ischaemic heart disease, congestive heart disease, cerebrovascular disease, hypertension, renal insufficiency, diabetes or hyperlipidaemia were recorded. The presence of coexisting conditions was assessed using the secondary diagnoses of the International Classification of Diseases, Ninth Revision, Clinical Modification (ICD9-CM). Adapting a classification scheme developed by Lee and colleagues [3], we calculated a Revised Cardiac Risk Index (RCRI) score for each patient, assigning one point for each of the following risk factors (defined as in the original description made by Lee et al.): high-risk surgery, ischaemic heart disease, congestive heart disease, cerebrovascular disease, renal insufficiency and diabetes mellitus.

\section{Functional capacity}

Functional capacity before surgery was evaluated by the ability to handle personal and instrumental ADL, assessed by a questionnaire that evaluates the functional independence of the individual in performing personal activities of daily living (P-ADL) and instrumental activities of daily living (I-ADL). This evaluation was completed again at six months after PACU discharge; on the same occasion, the patients completed a questionnaire on Health-Related Quality of Life.

\section{Medical Outcome Survey Short-Form 36 (SF-36)}

Health-related quality of life was assessed by the Medical Outcomes Study Short-form Health Survey (SF-36) [10]. This contains 36 questions that evaluate eight health domains considered to be important for patient wellbeing and health status. These domains reflect physical health, mental health, and the impact of health on daily functioning. The eight multiple-item domains encompass physical functioning (ten items), social functioning (two 
items), role limitations caused by physical problems (four items), role limitations caused by emotional problems (three items), mental health (five items), energy and vitality (four items), pain (two items) and general perception of health (five items). There is one further unscaled item that addresses self-reported changes in the respondent's health status during the past year. For each item, scores are coded, summed and transformed to a scale from 0 (worst possible health state measured by the questionnaire) to 100 (best possible health state). Scores can be aggregated to measures representing a physical health summary scale (consisting of physical functioning, physical role, pain and general health) and a mental health summary scale (vitality, social functioning, emotional role and mental health) [4].

The answers to the question in SF-36 about selfreported changes in health status ("compared to one year ago, how you would rate your health in general now?") were dichotomized as better, about the same or worse than one year ago.

To minimize distress to the next of kin, each patient's records were checked on the hospital information system after six months to ascertain whether he or she was still alive. A copy of a formal letter was sent to all known survivors accompanied by a return envelope and a validated Portuguese SF-36 self-report form [11,12]. This version of the SF-36 has been validated for the study population in the Porto region from which the subjects of this report were drawn [18]. Scores for all domains obtained for patients after AFB were compared with the published [18] values for this urban population.

We also compared the scores on all SF-36 domains for patients after AFB surgery with scores obtained for other PACU patients who were not submitted to AFB surgery.

\section{Activities of Daily Living (ADL)}

The personal ADL considered were bathing, dressing, going to the toilet, transferring from bed to chair, continence and feeding. The instrumental ADL considered were cleaning, food shopping, public transportation and cooking. This questionnaire was based on Katz' Index of Independence in ADL [19] and Lawton IADL [15] scales. Answers were also categorized into two groups, able or unable to perform each activity or group of activities. Patients were classified by their ability to perform physical and psychosocial ADL and four categories were possible: (a) I-ADL and P-ADL independent, (b) I-ADL dependent but P-ADL independent, (c) P-ADL dependent but I-ADL independent and (d) both P-ADL and I-ADL dependent.

\section{Outcome}

The outcome endpoints considered were: (1) Functional capacity and ADL - patients were considered dependent whether they were dependent in at least one I-ADL or
P-ADL activity; (2) Quality of life - quality of life was evaluated at six months after PACU discharge; (3) Mortality - patients were considered survivors if they were alive six months after PACU discharge.

\section{Statistical methods}

Descriptive analyses of variables were used to summarize data and the Mann-Whitney $U$ test was used to compare continuous variables between two groups of subjects; chi-square or Fisher's exact test was used to compare proportions between two groups of subjects.

To identify independent predictors of mortality univariate analysis was performed using simple binary logistic regression with an odds ratio (OR) and 95\% confidence interval $(\mathrm{CI})$ with the following independent variables: type of surgery, age, gender, BMI, ASA-PS, troponin I blood levels and temperature at admission to the PACU, comorbidities, RCRI score, duration of anaesthesia, and severity of disease scores (APACHE II and SAPS II). All variables were deemed to be significant if $P<0.05$.

Multiple regression binary logistic with forward conditional elimination was used to examine covariates and to identify independent predictors of mortality. In this model covariates with a univariate $p \leq 0.05$ in the univariate analysis were entered.

The Mann-Whitney U test and "t test" for independent groups were used to compare population means.

SPSS for Windows version 16.0 (SPSS, Chicago, IL) was used to analyze the data.

\section{Results}

During the study period there were 1597 admissions in the PACU and 75 patients met the inclusion criteria. The characteristics of all patients enrolled in the study are given in Table 1.

Ninety-seven percent were male. The median age was 64 years (minimum 41, maximum 80), median SAPS II was 18 (range 7-69) median APACHE II was 9 (range 425 ) and median LOS in the PACU was 44 hours. Seven patients (9\%) died during hospital stay.

Forty-eight patients had complex aorto-iliac occlusive disease and surgery was performed on 27 patients to treat aortic aneurysm.

Compared to those who had ABF surgery because of occlusive aortic disease, patients submitted to ABF surgery for correction of abdominal aortic aneurysm were older (median 70 versus 59 years, $P<0.001$ ), had higher BMI (median 26 versus $23, P=0.004$ ), had lower temperature (median 34.2 versus $34.8, \mathrm{P}=0.029$ ) and higher troponin I at admission to the PACU (median 0.04 versus $0.01, P=0.029$ ) and were more severely ill (median SAPS II 23 versus $15, P=0.002$ and median APACHE II 11 versus $9, P=0.012$ ). 
Table 1 Patient characteristics and outcome

\begin{tabular}{|c|c|c|c|c|}
\hline Variable & $\begin{array}{c}\text { AFB } \\
(n=75)\end{array}$ & $\begin{array}{c}\text { ANE } \\
(n=27)\end{array}$ & $\begin{array}{c}\text { AOD } \\
(n=48)\end{array}$ & $\mathbf{P}$ \\
\hline Age in years, median (IQR) & $64(57-72)$ & $70(64-75)$ & $59(53-68)$ & $<0.001^{\mathrm{c}}$ \\
\hline Age group, n (\%) & & & & $0.001^{\mathrm{a}}$ \\
\hline$\geq 65$ years & $36(48)$ & $20(74)$ & $16(33)$ & \\
\hline$<65$ years & $39(52)$ & $7(26)$ & $32(67)$ & \\
\hline Sex, n (\%) & & & & $0.406^{b}$ \\
\hline Male & $73(97)$ & $27(100)$ & $46(96)$ & \\
\hline Female & $2(3)$ & $0(0)$ & $2(4)$ & \\
\hline ASA physical status & & & & $0.174^{b}$ \\
\hline$|/| \mid$ & $26(35)$ & $7(26)$ & $19(40)$ & \\
\hline III/IV & $49(65)$ & $20(74)$ & $29(60)$ & \\
\hline Body Mass Index in $\mathrm{Kg} / \mathrm{m}^{2}$, median (IQR) & $24(21-27)$ & $26(24-31)$ & $23(21-26)$ & $0.004^{c}$ \\
\hline Duration of anaesthesia (min.), median (IQR) & $300(270-360)$ & $300(270-360)$ & $300(264-357)$ & $0.519^{c}$ \\
\hline Temperature at PACU admission, median (IQR) & $34.5(33.4-35.9)$ & $34.2(32.5-35.1)$ & $34.8(33.9-36.0)$ & $0.029^{c}$ \\
\hline Troponin I at PACU admission, median (IQR) & $0.09(0.01-0.04)$ & $0.04(0.01-0.16)$ & $0.01(0.01-0.04)$ & $0.029^{c}$ \\
\hline Hypertension, n (\%) & $55(73)$ & $23(85)$ & $32(67)$ & $0.068^{b}$ \\
\hline Hyperlipidemia, n (\%) & $37(49)$ & $16(59)$ & $21(44)$ & $0.197^{\mathrm{a}}$ \\
\hline High-risk surgery, n (\%) & $75(100)$ & $27(100)$ & $48(100)$ & - \\
\hline Ischaemic heart disease, n (\%) & $32(43)$ & $11(41)$ & $21(44)$ & $0.800^{\mathrm{a}}$ \\
\hline Congestive heart disease, $\mathrm{n}(\%)$ & $19(25)$ & $6(22)$ & $13(27)$ & $0.431^{b}$ \\
\hline Cerebrovascular disease, n (\%) & $7(9)$ & $1(4)$ & $6(13)$ & $0.204^{b}$ \\
\hline Renal insufficiency & $3(4)$ & $1(4)$ & $2(4)$ & $0.707^{\mathrm{b}}$ \\
\hline Insulin therapy for diabetes, n (\%) & $3(4)$ & $1(4)$ & $2(4)$ & $0.707^{b}$ \\
\hline Total RCRI & & & & $0.440^{\mathrm{a}}$ \\
\hline$\leq 2$ & $35(47)$ & $11(41)$ & $24(50)$ & \\
\hline Katz scale, median (IQR) & $0(0-0)$ & $0(0-0)$ & $0(0-0)$ & $0.459^{c}$ \\
\hline Dependency in I-ADL, n (\%) & $1(1)$ & $0(0)$ & $1(2)$ & $0.646^{\mathrm{b}}$ \\
\hline Lawton I-ADL, median (IQR) & $7(7-7)$ & $7(7-7)$ & $7(7-7)$ & $0.241^{c}$ \\
\hline Dependency in P-ADL, $\mathrm{n}(\%)$ & $6(8)$ & $1(4)$ & $5(10)$ & $0.290^{\mathrm{b}}$ \\
\hline SAPS II, median (P25-75) & $18(13-27)$ & $23(18-33)$ & $15(12-22)$ & $0.002^{c}$ \\
\hline APACHE II, median (IQR) & $9(7-13)$ & $11(8-15)$ & $9(6-11)$ & $0.012^{c}$ \\
\hline PACU length of stay (hours), median (IQR) & $44(36-68)$ & $43(21-102)$ & $44(40-68)$ & $0.603^{c}$ \\
\hline Hospital length of stay (days), median (IQR) & $11(8-28)$ & $11(8-24)$ & $11(8-30)$ & $0.475^{c}$ \\
\hline Mortality in PACU, n (\%) & $3(4)$ & $0(0)$ & $3(6)$ & $0.256^{\mathrm{b}}$ \\
\hline Mortality in hospital, n (\%) & $7(9)$ & $2(7)$ & $5(10)$ & $0.507^{\mathrm{b}}$ \\
\hline Mortality at 6 months follow-up & $9(12)$ & $4(14)$ & $5(10)$ & $0.414^{b}$ \\
\hline
\end{tabular}

${ }^{\mathrm{a}}$ Pearson $\chi^{2},{ }^{\mathrm{b}}$ Fisher's exact test, ${ }^{\mathrm{c}}$ Mann-Whitney $\mathrm{U}$ test, IQR, interquartile range

AFB, aorto-bifemoral bypass surgery; ANE, aneurysmatic disease; AOD, aortic occlusive disease

RCRI, Revised Cardiac Risk Index I-ADL, Instrumental Activities of Daily Living; P-ADL, Personal Activities of Daily Living; SAPS II, Simplified Acute Physiology Score, APACHE II Acute Physiology \& Chronic Health Evaluation PACU, Post Anaesthesia Care Unit; IQR, interquartile range

Sixty-eight patients were discharged from hospital; two died before the six-month evaluation (12\% global mortality at the time of evaluation). Of the remaining 66 patients, 16 (24\%) did not answer the questionnaires at six months follow-up but were known to be alive.

The characteristics of all patients who were still alive at six-month follow-up are presented in Table 2. Of these 50 participants, $98 \%$ were male and the median age was 64 years, median SAPS II was 18 , median APACHE II was 9 and median PACU LOS was 43 hours. There were no statistically significant differences between participants and non-participating patients in respect of the variables studied.

\section{Mortality}

Patients submitted to ABF because of aortic occlusive disease had higher mortality rates at the PACU (6\% versus $0 \%$ ) and during hospital stay (10\% versus $7 \%$ ), but had lower mortality rates (10\% versus $14 \%$ ) at six months follow-up. However, these differences were not statistically significant. 
Table 2 Comparison of characteristics between respondents and non-respondents

\begin{tabular}{|c|c|c|c|}
\hline Variable & $\begin{array}{l}\text { Respondents } \\
(\mathrm{n}=50)\end{array}$ & $\begin{array}{c}\text { Non-respondents } \\
(\mathrm{n}=16)\end{array}$ & $P$ value \\
\hline Type of surgery & & & $0.407^{b}$ \\
\hline AFB for Aneurysmatic disease & $19(37)$ & $4(29)$ & \\
\hline AFB for occlusive disease & $31(63)$ & $12(71)$ & \\
\hline Age in years, median (IQR) & $64(56-70)$ & $61(55-70)$ & $0.884^{c}$ \\
\hline Sex, n (\%) & & & $0.452^{\mathrm{b}}$ \\
\hline Male & $48(98)$ & $16(94)$ & \\
\hline Female & $1(2)$ & $1(6)$ & \\
\hline $\mathrm{BMI}\left(\mathrm{Kg} / \mathrm{m}^{2}\right)$, median (IQR) & $23(20-24)$ & $25(22-27)$ & $0.393^{c}$ \\
\hline Duration of anaesthesia (min.), median (IQR) & $300(270-336)$ & $300(240-360)$ & $0.729^{c}$ \\
\hline Temperature at admission, median (IQR) & $34.5(33.2-35.6)$ & $34.5(33.3-36.0)$ & $0.084^{c}$ \\
\hline ASA Physical status & & & $0.481^{a}$ \\
\hline$|/| \mid$ & $18(37)$ & $7(41)$ & \\
\hline III/IV & $31(63)$ & $10(59)$ & \\
\hline Troponin at admission, median (IQR) & $0.04(0.01-0.04)$ & $0.01(0.01-0.05)$ & $0.780^{b}$ \\
\hline Total RCRI & & & $0.442^{\mathrm{a}}$ \\
\hline$\leq 2$ & $26(53)$ & $8(47)$ & \\
\hline$>2$ & $23(47)$ & $9(53)$ & \\
\hline Hypertension n.(\%) & $36(74)$ & $13(77)$ & $0.541^{\mathrm{b}}$ \\
\hline Hyperlipidemia, n (\%) & $22(45)$ & $11(65)$ & $0.130^{b}$ \\
\hline Ischaemic heart disease & $23(47)$ & $6(35)$ & $0.293^{b}$ \\
\hline History of congestive heart disease & $11(22)$ & $2(12)$ & $0.283^{b}$ \\
\hline History of cerebrovascular disease & $1(2)$ & $2(11)$ & $0.050^{b}$ \\
\hline Insulin therapy for diabetes & $3(6)$ & $0(0)$ & $0.403^{b}$ \\
\hline Renal insufficiency & $1(2)$ & $0(0)$ & $0.742^{b}$ \\
\hline Dependency in P-ADL & $1(2)$ & $0(0)$ & $0.817^{b}$ \\
\hline Dependency in I-ADL & $6(12)$ & $0(0)$ & $0.279^{b}$ \\
\hline Previous Katz, median (IQR) & $0(0-0)$ & $0(0-0)$ & $0.636^{c}$ \\
\hline Previous Lawton, median (IQR) & $7(7-7)$ & $7(7-7)$ & $0.226^{c}$ \\
\hline SAPS $\|$, median (IQR) & $18(13-24)$ & $15(12-23)$ & $0.643^{c}$ \\
\hline APACHE II, median (IQR) & $9(7-13)$ & $8(5-11)$ & $0.121^{b}$ \\
\hline Hours of ICU length of stay, median (IQR) & $43(23-68)$ & $44(40-56)$ & $0.467^{c}$ \\
\hline Days of hospital length of stay, median (IQR) & $11(8-20)$ & $15(8-32)$ & $0.210^{c}$ \\
\hline
\end{tabular}

a Pearson $\chi^{2}$, ${ }^{b}$ Fisher's exact test, ' Mann-Whitney $U$ test, IQR, interquartile range

AFB, aorto-bifemoral bypass surgery; BMI, Body Mass Index; RCRI, Revised Cardiac Risk Index; I-ADL, Instrumental Activities of Daily Living; P-ADL, Personal Activities of Daily Living; SAPS II, Simplified Acute Physiology Score; APACHE II Acute Physiology \& Chronic Health Evaluation PACU; PACU, Post Anaesthesia Care Unit.

Univariate analysis identified the following independent predictors for mortality at 6 months follow-up (Table 3): age (OR $1.15,95 \%$ CI 1.03 to $1.28, P=0.015$ ), congestive heart disease (OR 8.15, 95\% CI 1.80 to 37.01 , $P=0.007$ ), renal insufficiency (OR $18.57,95 \%$ CI 1.49 to $231.7, P=0.023$ ) and RCRI score (OR 8.50, 95\% CI 1.01 to $71.83, P=0.049$ for RCRI $>2$ ), SAPS II (OR 1.09, $95 \%$ CI 1.04-1.14, $\mathrm{p}=0.001)$ and APACHE II (OR 1.51, 95\% CI 1.17-1.83, $\mathrm{p}=0.001$ ).

Multiple logistic regression analysis with forward conditional elimination was used to examine covariate effects of each factor on mortality (Table 4). The regression model included all variables with statistical significance in the univariate analysis for determinants of mortality. This analysis showed that independent risk factors for hospital mortality, after adjustment for age, congestive heart disease, renal insufficiency, RCRI, SAPS II and APACHE II were congestive heart disease (OR 9.86, 95\% CI 1.48 to 65.55, $P=0.018$ ), and APACHE II (OR $1.40,95 \% \mathrm{CI}$ 1.11 to $1.76, P=0.005)$.

\section{Functional capacity and ADL}

Six months after discharge from the PACU, $62 \%$ and $20 \%$ of patients, respectively, were dependent in at least one activity in instrumental and personal ADL (Table 5).

Scores on the Katz and Lawton scales were significantly different after surgery, indicating more 
Table 3 Univariate analysis for determinants of mortality after aorto-bifemoral bypasses surgery

\begin{tabular}{|c|c|c|c|}
\hline & nonsurvivors/survivors & & \\
\hline Variable & $n=9 n=66$ & Odds ratio $(95 \% \mathrm{Cl})$ & $\mathbf{P}$ \\
\hline \multicolumn{4}{|l|}{ Type of AFB surgery } \\
\hline for Aneurysmatic disease & $4(44) / 23(35)$ & $1.50(0.36-6.12)$ & 0.575 \\
\hline for occlusive disease & $5(56) / 43(65)$ & 1 & \\
\hline Age & $73(67-76) / 55(62-70)$ & $1.15(1.03-1.28)$ & 0.015 \\
\hline Gender & & - & 0.999 \\
\hline Female & $0(0) / 2(3)$ & & \\
\hline Male & $9(100) / 64(97)$ & & \\
\hline BMI, median & $20(21-29) / 24(21-26)$ & $0.96(0.74-1.24)$ & 0.733 \\
\hline Duration of anaesthesia (min.) & $333(330-450) / 300(264-357)$ & $1.01(1.00-1.01)$ & 0.117 \\
\hline \multicolumn{4}{|l|}{ ASA Physical status } \\
\hline$|/| \mid$ & $1(11) / 25(38)$ & 1 & \\
\hline III/IV & $8(89) / 41(62)$ & $4.88(0.58-41.36)$ & 0.146 \\
\hline Temperature at admission & $34.3(34.0-35.1) / 34.5(33.3-35.9)$ & $0.96(0.61-1.50)$ & 0.848 \\
\hline Troponin at admission & $0.01(0.01-0.05) / 0.02(0.01-0.04)$ & $0.001(0-3500)$ & 0,656 \\
\hline Hypertension & $6(67) / 49(74)$ & $0.63(0.16-3.09)$ & 0.631 \\
\hline Hyperlipidemia & $4(44) / 33(50)$ & $0.80(0.20-3.25)$ & 0.755 \\
\hline Ischaemic heart disease & $3(33) / 29(44)$ & $0.64(0.15-2.77)$ & 0.549 \\
\hline Congestive heart disease & $6(67) / 13(20)$ & $8.15(1.80-37.01)$ & 0.007 \\
\hline Cerebrovascular disease & $2(22) / 5(8)$ & $3.49(0.57-21.45)$ & 0.178 \\
\hline Insulin therapy for diabetes & $0(0) / 3(5)$ & - & 0.999 \\
\hline Renal insufficiency & $2(22) / 1(2)$ & $18.57(1.49-231.7)$ & 0.023 \\
\hline \multicolumn{4}{|l|}{ RCRI } \\
\hline$\leq 2$ & $1(11) / 34(52)$ & 1 & \\
\hline$>2$ & $8(89) / 32(49)$ & $8.50(1.01-71.83)$ & 0.049 \\
\hline Previous score in Katz scale & $0 / 0$ & - & 0.999 \\
\hline Previous score in Lawton scale & $7(7-7) / 7(4-7)$ & $0.76(0.48-1.18)$ & 0.215 \\
\hline SAPS II, median & $33(19-60) / 18(13-23)$ & $1.09(1.04-1.14)$ & 0.001 \\
\hline APACHE II & $13(15-25) / 8(6-11)$ & $1.51(1.17-1.83)$ & 0.001 \\
\hline Length of PACU stay (hours) & $93(45-140) / 44(34-66)$ & $1.01(1.00-1.02)$ & 0.066 \\
\hline Length of Hospital stay (days) & $9(8-32) / 11(8-27)$ & $1.00(0.98-1.02)$ & 0.990 \\
\hline
\end{tabular}

AFB, aorto-bifemoral bypass surgery; BMI, Body mass index; ASA, American Society of anesthesiologists, COPD, Chronic obstructive pulmonary disease; RCRI, Revised cardiac risk index; PACU, Post Anaesthesia Care Unit, SAPS, Simplified Acute Physiology Score; APACHE II Acute Physiology \& Chronic Health Evaluation

Table 4 Multivariate regression analysis for predictors of mortality.

\begin{tabular}{lcccc}
\hline Variable & $\begin{array}{c}\text { Simple } \\
\text { OR }\end{array}$ & p & $\begin{array}{c}\text { Adjusted* OR (95\% } \\
\text { CI) }\end{array}$ & p* $^{*}$ \\
\hline Age & 1.15 & 0.015 & & \\
Renal insufficiency & 18.57 & 0.023 & & \\
Congestive heart & 8.15 & 0.007 & $9.86(1.48-65.55)$ & 0.018 \\
disease & & & & \\
RCRI & 1 & & & \\
$\quad \leq 2$ & 8.50 & 0.049 & & \\
$\quad>2$ & 1.09 & 0.001 & & \\
SAPS II & 1.51 & 0.001 & $1.40(1.11-1.76)$ & 0.005 \\
APACHE II & & & &
\end{tabular}

a Logistic regression analysis with stepwise forward method was used with an entry criterion of $p<0.05$ and a removal criterion of $p>0.1$.

SAPS, Simplified Acute Physiology Score; APACHE II, Acute Physiology and Chronic health Evaluation.

${ }^{*}$ Adjusted to age, renal insufficiency, congestive heart disease, RCRI, SAPS II and APACHE II.
Table 5 Dependency and self reported changes in health in general 6 months after PACU discharge $(n=50)$

\begin{tabular}{|c|c|c|c|}
\hline Variable & $\begin{array}{l}\text { Before } \\
\text { surgery } \\
(\mathrm{n}=50)\end{array}$ & $\begin{array}{c}6 \text { months after } \\
\text { AFB } \\
(\mathrm{n}=50)\end{array}$ & $P$ \\
\hline \multicolumn{4}{|l|}{$\begin{array}{l}\text { Personal activities of daily } \\
\text { living }\end{array}$} \\
\hline Katz scale & 0 & 0 & 0.040 \\
\hline $\begin{array}{l}\text { Dependency in P-ADL, } \mathrm{n} \\
(\%)\end{array}$ & $1(2)$ & $10(20)$ & 0.796 \\
\hline \multicolumn{4}{|l|}{$\begin{array}{l}\text { Instrumental activities of } \\
\text { daily living }\end{array}$} \\
\hline Lawton scale & $7.0(7.0-7.0)$ & $5.0(3.8-7.0)$ & $<0.001$ \\
\hline $\begin{array}{l}\text { Dependency in I-ADL, } \mathrm{n} \\
(\%)\end{array}$ & $6(12)$ & $31(62)$ & 0.271 \\
\hline
\end{tabular}

AFB, aorto-bifemoral bypass surgery; I-ADL, Instrumental Activities of Daily Living;

P-ADL, Personal Activities of Daily Living 
dependency. There were no differences in percentage of dependency for ADL-I and ADL-P.

\section{Quality of Life Measures}

Overall, 64\% stated that their health in general was better on the day of testing and $8 \%$ considered it to be worse at that time than previously (six months before PACU discharge). There were no statistically significant differences between patients' baseline characteristics and worse self-reported general level of health.

Patients submitted to AFB because of occlusive disease had worse SF-36 scores for role physical (median 43.8 versus 75.0) and for general health perception (median 42.0 versus 50.0 ) than patients with aneurysmatic disease (Table 6).

Compared to values obtained from the general urban population of Porto, the SF-36 sub-scores of all patients submitted to AFB were worse in all domains (Table 7).

Patients submitted to AFB did not differ in any of the SF-36 domains from other PACU patients who were not submitted to AFB (Table 8).

\section{Discussion}

AFB surgery is a current treatment for two types of complex disease: aorto-iliac occlusive and abdominal aortic aneurysms. This surgery is performed to improve long-term survival and to preserve function.

In the present study we found that independent predictors of mortality before six months after AFB surgery were higher APACHE II scores on admission to the PACU and congestive heart disease.

In a study published by Thomas S. Huber et al. [20], the authors studied aortic reconstructions performed for aneurismal or occlusive disease. They found that multiple systemic organ failure (MSOF) was a leading cause of death and admitted that patient age, APACHE II, and a diagnosis of sepsis at the time of ICU admission had previously been identified as risk factors for the

Table 6 SF-36 6 months after AFB

\begin{tabular}{lccc}
\hline Variable & $\begin{array}{c}\text { Aneurysmatic } \\
\text { disease }\end{array}$ & occlusive disease & $\mathbf{p}$ \\
\hline $\begin{array}{l}\text { SF-36 domains } \\
\text { physical function }\end{array}$ & $70.0(40.0-75.0)$ & $50.0(20.0-70.0)$ & $0.094^{\mathrm{a}}$ \\
$\begin{array}{l}\text { role physical } \\
\text { bodily pain }\end{array}$ & $75.0(37.5-81.3)$ & $43.8(18.8-75.0)$ & $0.047^{\mathrm{a}}$ \\
general health & $62.0(51.0-84.0)$ & $51.0(41.0-74.0)$ & $0.160^{\mathrm{a}}$ \\
perception & $50.0(35.0-77.0)$ & $42.0(20.0-55.0)$ & $0.048^{\mathrm{a}}$ \\
Vitality & & & \\
social functioning & $62.5(37.5-87.5)$ & $50.0(37.5-75.0)$ & $0.338^{\mathrm{a}}$ \\
role emotional & $50.0(33.3-100)$ & $50.0(25.0-75.0)$ & $0.308^{\mathrm{a}}$ \\
mental health & $52.0(32.0-80.0)$ & $48.0(32.0-68.0)$ & $0.378^{\mathrm{a}}$ \\
\hline
\end{tabular}

${ }^{a}$ Mann-Whitney $U$ test

SF-36, Short-form 36; AFB, aorto-bifemoral bypass surgery
Table 7 SF-36 after AFB and population SF-36 means

\begin{tabular}{|c|c|c|c|}
\hline Variable & $\begin{array}{c}\text { After AFB } \\
(n=50)\end{array}$ & $\begin{array}{c}\text { urban } \\
\text { population } \\
(\mathrm{n}=1326)\end{array}$ & $p$ \\
\hline SF-36 domains & mean \pm sd & mean \pm sd & \\
\hline physical function & $52.5 \pm 27.5$ & $75.4 \pm 23.6$ & $<0.001^{a}$ \\
\hline role physical & $52.4 \pm 32.9$ & $76.7 \pm 26.1$ & $<0.001^{\mathrm{a}}$ \\
\hline bodily pain & $56.9 \pm 26.1$ & $65.7 \pm 26.2$ & $0.019^{\mathrm{a}}$ \\
\hline $\begin{array}{l}\text { general health } \\
\text { perception }\end{array}$ & $46.9 \pm 25.1$ & $59.5 \pm 19.8$ & $<0.001^{a}$ \\
\hline Vitality & $34.8 \pm 16.8$ & $57.2 \pm 21.1$ & $<0.001^{a}$ \\
\hline social functioning & $59.0 \pm 26.5$ & $76.0 \pm 24.1$ & $<0.001^{a}$ \\
\hline role emotional & $54.0 \pm 33.7$ & $76.9 \pm 25.8$ & $<0.001^{a}$ \\
\hline mental health & $49.7 \pm 23.8$ & $66.1 \pm 22.8$ & $<0.001^{a}$ \\
\hline
\end{tabular}

${ }^{a} \mathrm{t}$ test for independent groups

SF-36, Short-form 36; AFB, aorto-bifemoral bypass surgery

Table 8 Results of SF-36 administration compared to results in surgical patients 6 months after PACU discharge

\begin{tabular}{|c|c|c|c|}
\hline Variable & $\begin{array}{l}\text { after AFB } \\
(\mathrm{n}=50)\end{array}$ & $\begin{array}{l}\text { after other } \\
\text { PACU } \\
\text { surgical } \\
\text { patients } \\
(\mathrm{n}=737)\end{array}$ & $p$ \\
\hline \multicolumn{4}{|l|}{ SF-36 domains } \\
\hline physical function & $55.0(30.0-71.3)$ & $55.0(25.0-80.0)$ & $0.811^{\mathrm{a}}$ \\
\hline role physical & $50.0(29.7-81.3)$ & $43.8(18.8-75.0)$ & $0.225^{a}$ \\
\hline bodily pain & $52.0(41.0-74.0)$ & $52.0(32.0-80.0)$ & $0.984^{a}$ \\
\hline $\begin{array}{l}\text { general health } \\
\text { perception }\end{array}$ & $45.0(30.0-65.5)$ & $45.0(25.0-67.0)$ & $0.863^{\mathrm{a}}$ \\
\hline vitality & $31.3(20.8-42.7)$ & $33.3(20.8-45.8)$ & $0.896^{a}$ \\
\hline social functioning & $62.5(37.587 .5)$ & $62.5(37.5-87.5)$ & $0.728^{\mathrm{a}}$ \\
\hline role emotional & $50.0(25.0-83.3)$ & $50.0(25.0-83.3)$ & $0.485^{\mathrm{a}}$ \\
\hline mental health & $48.0(32.0-68.0)$ & $52.0(32.0-68.0)$ & $0.854^{a}$ \\
\hline
\end{tabular}

${ }^{a}$ Mann-Whitney $U$ test

SF-36, Short-form 36; AFB, aorto-bifemoral bypass surgery

development of MSOF. In that study the mortality rate did not vary with the indication for aortic reconstruction (aneurismal disease, 6.3\%; occlusive disease, 5.7\%; combined aneurismal/occlusive, 8.3\%). In that study they also concluded that history of congestive heart disease was a predictor for mortality and the other predictors were patient age, low ejection fraction, duration of operative time, and performance of additional procedures.

Concerning only aortic occlusive disease, Morris-Stiff et al. [21] found a 30-day mortality of $10.4 \%$, with a 1year patient and graft survival of $80 \%$; for open elective treatment of aneurismal disease but most large series describe hospital mortality rates of 3 to $6 \%[22,23]$ although the existence of pre-existing comorbidities were associated with higher mortality rates. 
In the univariate analysis we identified six risk factors for mortality after AFB: Age, renal insufficiency, congestive heart disease, RCRI, SAPS II and APACHE II.

In the study of Dimick et al. [24] the authors also identified age of 65 years or older as a risk factor for mortality after AFB and Teufelsbauer et al. [25] found five independent predictors for mortality after open surgical repair of infrarenal aortic aneurysms. Two of these predictors were similarly found in our univariate analises: age and renal dysfunction. Beyond these they also found type of operation, pulmonary dysfunction and diabetes.

Our results differ from those of Wolters et al. [26], who studied ASA physical status, APACHE-II, and operative severity score for enumeration of mortality and morbidity (POSSUM) classification and SAPS, and concluded that none of the systems analyzed separately was useful for determining morbidity and mortality in patients after aorto-iliac surgery.

We evaluated health related quality of life six months after discharge from the PACU according to the American College of Surgeons and the American Society of Vascular Surgery, both of which have promoted the use of SF-36 in the surgical population [27,28]; this questionnaire has been validated for patients with vascular diseases [29].

In the present study we examined the effect of AFB surgery on quality of life and independence in activities of daily living. To study the impact of the procedure on quality of life we used the self-evaluated health transition item of the SF-36 questionnaire. This item is not used in scoring the scales but has been shown to be useful for estimating average change in health status over the year prior to its administration [30].

Although patients submitted to AFB because of occlusive disease were younger than those submitted to AFB because of aneurysmatic disease, they had lower SF-36 scores in two domains: role physical and general health perception. As role physical refers to the extent to which a respondent's performance of roles in daily activities is impeded by their physical state of health, and individual general health perception is measured by ratings such as excellent, very good, good, fair or poor, these differences may reflect the burden of dependency and the perception of a chronic disease.

Comparisons with a general (taken as "control") population are difficult to interpret because patients subjected to AFB generally perceive themselves as chronically ill. Thus, our finding that quality of life was worse in our patients than in the general population was not unexpected. A comparison with other PACU surgical patients with similar demographic characteristics from the same urban area seemed more appropriate for establishing comparisons with AFB patients, and the results, which showed no differences, are comprehensible.

The patients in our study had higher degrees of dependency in instrumental and personal ADL after surgery, which was not entirely unexpected in view of the extent of comorbidities and the natural history of their disease. It seems paradoxical that these patients, despite being more dependent, stated that their quality of life was better than before surgery. We think this could be explained by their expectation that surgical intervention would promote better health.

The limitations of this study include its retrospective nature, the relatively small number of patients and the fact that the patient population in the study is inhomogeneous. We have included patients submitted to ABF surgery done for aneurysmal aorto-iliac disease and patients with occlusive arterial disease. The first group of patients are asymptomatic and the procedure is prophylactic in its nature but in the second group ABF surgery is directed towards improvement of the arterial blood supply to the lower extremities, thereby improving the signs and symptoms. This may have influenced differences in the quality of life during the postoperative 6 month period between these two groups of patients.

Another limitation is that we did not apply the SF-36 questionnaire before surgery so it was not possible to compare quality of life of patients before and after surgery, as in the prospective study by Aljabri et al. [31] on patients after abdominal aortic aneurysm repair. Nevertheless, we used the SF-36 question about self-reported changes in health status ("compared to one year ago, how would you rate your health in general now?") to conclude that general health was better for most patients on the day they completed the SF-36 than before surgery.

\section{Conclusion}

This study shows that congestive heart disease and APACHE II were considered risk factors for mortality at six months follow-up. Survivors who have undergone AFB perceive an improved quality of life although they are more dependent in ADL tasks and have worse scores in almost all SF-36 than the population to which they belong.

\section{Author details}

${ }^{1}$ Department of Anesthesia, Hospital de São João, Porto, Portugal. ${ }^{2}$ Department of Hygiene and Epidemiology - University of Porto Medical School Porto - Portugal.

\section{Authors' contributions}

All people listed as authors contributed to the preparation of the manuscript and no person or persons other than the authors listed have contributed significantly to its preparation. 
Each listed author participated in the work to the extent that they could all publicly defend its content. They all read the manuscript before its submission for publication and are prepared to sign a statement stating they had read the manuscript and agree to its publication.

\section{Competing interests}

The authors declare that they have no competing interests.

Received: 28 May 2009 Accepted: 18 March 2010

Published: 18 March 2010

\section{References}

1. Carsten CG, Kalbaugh CA, Langan EM, Cass AL, Cull DL, Snyder BA, York JW, Taylor SM: Contemporary outcomes of iliofemoral bypass grafting for unilateral aortoiliac occlusive disease: a 10-year experience. Am Surg 2008, 74(6):555-559.

2. Dimick JB, Cowan JA Jr, Henke PK, Wainess RM, Posner S, Stanley JC, Upchurch GR Jr: Hospital volume-related differences in aorto-bifemoral bypass operative mortality in the United States. J Vasc Surg 2003, 37(5):970-975.

3. Lee TH, Marcantonio ER, Mangione CM, Thomas EJ, Polanczyk CA, Cook EF, Sugarbaker DJ, Donaldson MC, Poss RHK, Ludwig LE, et al: Derivation and prospective validation of a simple index for prediction of cardiac risk of major noncardiac surgery. Circulation 1999, 100:1043-1049.

4. Ware JE, Snow KK, Kosinski M, Gandek B: SF-36 health survey: Manual and interpretation guide. The Health Institute, Boston 1993.

5. Fernandez RR, Cruz JJ, Mata GV: Validation of a quality of life questionnaire for critically ill patients. Intensive Care Medicine 1996, 22:1034-1042

6. Niskanen M, Ruokonen E, Takala J, Rissanen P, Kari A: Quality of life after prolonged intensive care. Crit care Med 1999, 27:1132-1139.

7. Patrick DL, Danis M, Southerland LI, Hon G: Quality of life following intensive care. J Gen Intern Med 1988, 3:218-223.

8. The EuroQol Group: EuroQol - a new facility for the measurment of health-related quality of life. Health Policy 1990, 16:199-208.

9. McHorney CA, Ware JE, Raczek AE: The MOS 36 Item Short-Form Health Survey (SF-36): II. Psychometric and clinical tests of validity in measuring physical and mental health constructs. Med Care 1993, , 31: 247-263.

10. Ware JE, Sherbourne CD: The MOS 36-Item Short-Form Health Survey (SF36). I. Conceptual framework and item selection. Med Care 1992, 30:473-483.

11. Ferreira PL: Development of the Portuguese version of MOS SF-36. Part I. Cultural and linguistic adaptation. Acta Med Port 2000, 13(1-2):55-66.

12. Ferreira PL: Development of the Portuguese version of MOS SF-36. Part II-Validation tests. Acta Med Port 2000, 13(3):119-127.

13. Weinert CR, Gross CR, Kangas JR, Bury CL, Marinelli WA: Health-related quality of life after acute lung injury. Am J Respir Crit Care Med 1997, 156:1120-1128.

14. Katz S, Ford AB, Moskowitz RW, Jackson BA, Jaffe MW: Studies of illness in the aged. The index of ADL: a standardized measure of biological and psychosocial function. JAMA 1963, 185(Sep 21):914-919.

15. Lawton MP, Brody EM: Assessment of older people: Self-maintaining and instrumental activities of daily living. The Gerontologist 1969, 9(3):179-186.

16. Le Gall JR, Lemeshow S, Saulnier F: A new Simplified Acute Physiology Score (SAPS II) based on a European/North American multicenter study. JAMA 1993, 270:2957-2963.

17. Knaus WA, Draper EA, Wagner DP, Zimmerman JE: APACHE II: a severity of disease classification system. Crit Care Med 1985, 13:818-829.

18. Severo MSA, Lopes C, Barros H: Reliability and validity in measuring physical and mental health construct of the Portuguese version of MOS SF-36. Acta Med Port 2006, 19(4):281-287.

19. Katz S: Assessing self-maintenance: activities of daily living, mobility, and instrumental activities of daily living. J Am Geriatr Soc 1983, 31(12):721-727.

20. Huber TS, Harward TR, Flynn TC, Albright JL, Seeger JM: Operative mortality rates after elective infrarenal aortic reconstructions. J Vasc Surg 1995, 22(3):287-293.

21. Morris-Stiff G, Ogunbiyi S, Winter RK, Brown R, Lewis MH: Aortic replacement in aorto-occlusive disease: an observational study. BMC Surg 2008, 8:19.
22. Katz DJ, Stanley JC, Zelenock GB: Operative mortality rates for intact and ruptured abdominal aortic aneurysms in Michigan: an eleven-year statewide experience. J Vasc Surg 1994, 19(5):804-815.

23. Management of peripheral arterial disease (PAD). TransAtlantic InterSociety Consensus (TASC). Section C: acute limb ischaemia. Eur J VasC Endovasc Surg 2000, , 19 Suppl A: S115-143.

24. Dimick JB, Cowan JA Jr, Henke PK, Wainess RM, Posner S, Stanley JC, Upchurch GR Jr: Hospital volume-related differences in aorto-bifemoral bypass operative mortality in the United States. J Vasc Surg 2003, 37(5):970-975.

25. Teufelsbauer $H$, Prusa AM, Wolff $K$, Polterauer $P$, Nanobashvili J, Prager $M$, Hölzenbein T, Thurnher S, Lammer J, Schemper M, et al: Endovascular stent grafting versus open surgical operation in patients with infrarenal aortic aneurysms: a propensity score-adjusted analysis. Circulation 2002, 106(7):782-787.

26. Wolters $\mathrm{U}$, Mannheim $\mathrm{S}$, Wassmer $\mathrm{G}$, Brunkwall J: What is the value of available risk-scores in predicting postoperative complications after aorto-iliac surgery? A prospective non randomized study. J Cardiovasc Surg 2006, 47(2):177-185.

27. Reemtsma K, Morgan M: Outcomes assessment: a primer. Bull Am Coll Surg 1997, 82:34-39.

28. McDaniel MD, Nehler MR, Santilli SM, Hiatt WR, Regensteiner JG, Goldstone J, McCarthy WJ, White JV: Extended outcome assessment in the care of vascular diseases: revising the paradigm for the 21st century. Ad Hoc Committee to Study Outcomes Assessment, Society for Vascular Surgery/International Society for Cardiovascular Surgery, North American Chapter. J Vasc Surg 2000, 32(6):1239-1250.

29. Chetter IC, Spark JI, Doan P, DJ S, Kester RC: Quality of life analysis in patients with lower limb ischemia: suggestions for European standardization. Eur J Vasc Endovasc Surg 1997, 13:597-604

30. Ware JE Jr, Gandek B: Overview of the SF-36 Health Survey and the International Quality of Life Assessment (IQOLA) Project. J Clin Epidemiol 1998, 51:903-912.

31. Aljabri B, Al Wahaibi K, Abner D, Mackenzie KS, Corriveau MM, Obrand DI, Meshefedjian G, Steinmetz OK: Patient-reported quality of life after abdominal aortic aneurysm surgery: a prospective comparison of endovascular and open repair. J Vasc Surg 2006, 44(6):1182-1187.

\section{Pre-publication history}

The pre-publication history for this paper can be accessed here:http://www. biomedcentral.com/1471-2261/10/15/prepub

\section{doi:10.1186/1471-2261-10-15}

Cite this article as: Abelha et al:: Outcome and quality of life after aorto-bifemoral bypass surgery. BMC Cardiovascular Disorders 2010 10:15.

\section{Submit your next manuscript to BioMed Central and take full advantage of:}

- Convenient online submission

- Thorough peer review

- No space constraints or color figure charges

- Immediate publication on acceptance

- Inclusion in PubMed, CAS, Scopus and Google Scholar

- Research which is freely available for redistribution

Submit your manuscript at www.biomedcentral.com/submit
C Biomed Central 